\title{
GAMELAN SEKATEN \\ DAN PENYEBARAN ISLAM DI JAWA
}

\author{
Joko Daryanto \\ Universitas Sebelas Maret
}

\begin{abstract}
Abstrak
Penyebaran Islam di Jawa menggunakan berbagai cara ataupun metode dakwah penyebaran Islam. Salah satu sarana pendukung penyebaran Islam di Pulau Jawa adalah gamelan Sekaten. Perangkat gamelan ini merupakan perangkat gamelan yang dibunyikan untuk memperingati kelahiran Nabi Muhammad SAW, dibunyikan selama satu minggu di Bangsal Pagongan depan Masjid Agung Surakarta.Sebelum orang Jawa mengenal dan memeluk agama Islam, masyarakat Jawa telah memeluk agama Hindu dan Budha. Kondisi sosial psikologis masyarakat Jawa semacam itu rupanya menjadi hambatan para wali untuk menyebarkan agama Islam. Pada akhirnya Sunan Kalijaga mengusulkan agar menggunakan gamelan sebagai daya tarik awal bagi penyebaran agama Islam. Gamelan Sekaten yang digunakan sebagai sarana penyebaran agama Islam di Jawa diduga kuat memiliki nilai-nilai atau unsur-unsur Islam dalam perangkat tersebut.Setting masyarakat Jawa pada saat itu masih memiliki keyakinan yang sangat kuat terhadap agama Hindu dan Budha sehingga diperlukan alat bantu dalam hal ini gamelan Sekaten untuk memudahkan para wali menyebarkan agama Islam. Strategi dakwah dengan menggunakan gamelan Sekaten ternyata sangat menarik dan efektif untuk mengumpulkan orang. Diawali dengan ketertarikan terhadap bunyi gamelan Sekaten akhirnya masyarakat Jawa mengenal dan akhirnya memeluk Islam sebagai keyakinan. ProsesIslamisasi seperti itu selanjutnya disebutsebagai dakwah dengan menggunakan pendekatan kultural.
\end{abstract}

Kata kunci: gamelan, sekaten, Islam, Jawa

\begin{abstract}
The spreading of Islamic faith in Java uses many ways or methods to propagate Islamic faith. One of the medium which is support the spreading of Islam in Java is 'Gamelan Sekaten'. It is kind of an ensemble which is played on the occasion of Muhammad's birthday and played as long as 1 week in 'Bangsal Pagongan' in front of the Great Mosque Surakarta. Before Javanese people knowing and converting into Islamic faith, Javanese people have been converted into Hindu \& Buddhist faith. This psychological social condition of Javanese people becomes the obstacle for the nine muslim saints, Wali Sanga, to spread Islamic faith. Sunan Kalijaga suggested using 'gamelan' as the attractiveness of spreading Islam. The 'Gamelan Sekaten' which is used as a medium of spreading Islam in Java strongly assumed that this medium has value or element of Islam. The setting of Javanese people in that time still had a strong faith toward Hindu \& Buddhist faith, so it required a tool, in this case is a 'gamelan sekaten', to facilitate the nine muslim saints in spreading Islamic Faith.This religious proselytizing strategy which is use
\end{abstract}


'gamelan sekaten' as a medium appears to be very interesting \& effective to gather people. Begins with feel interest to 'gameln sekaten', finally, Javanese people know and convert into Islam as their faith. This Islamization process, called as religious proselytizing using cultural approach.

Key words: ‘Gamelan Sekaten'. Spreading of Islamic Faith, Cultural Approach

\section{PENDAHULUAN}

Karaton Surakarta yang merupakan kelanjutan dari Kerajaan Mataram Islam sampai saat ini masih berdiri kokoh baik bangunan maupun adat istiadat serta upacara tradisi yang masih dijaga kelestariannya. Oleh karena Karaton Surakarta masih menjaga tradisi dan adat istiadatnya maka sampai saat ini Karaton Surakarta masih memiliki seorang raja dengan segala kekuasaannya.Soemarsaid Moertono menyebutkan kekuasaan seorang raja Jawa digambarkan sebagai wenang misesa ing sanagari, artinya memegang kekuasaan tertinggi di seluruh negeri. Raja tidak hanya berkuasa atas negara dan harta benda, tetapi juga terhadap segenap kawula dengan kehidupan pribadinya. ${ }^{2}$ Pada masa Hindu raja adalah penguasa yang disejajarkan dengan dewa atau lebih dikenal dengan konsep dewaraja, namun pada masa kerajaan Islam konsep ini tidakberlaku lagi. Teologi Islam menempatkan raja sebagai khalifatullah atau wali Tuhan di dunia. Namun demikian penempatan ini tidak mengubah kekuasaan raja terhadap rakyatnya. ${ }^{3}$

Kerajaan Mataram (Islam) sampai dengan Karaton Surakarta menerapkan penempatan kedudukan raja sebagai khalifatullah sampai pada gelar kebesarannya. Raja yang menempati status sosial tertinggi di karaton tercermin pada nama, gelar, atau sebutan yang disandangnya. Peletak dasar wangsa Mataram, yaitu Senapati menggunakan sebutan panembahan, penggantinya,Anyakrawati, semula memakai panenibahan. Penguasa ketiga Anyakrakusuma sesudah memiliki wilayah yang luas memakai gelar susuhunan yang menunjukkan kedudukan yang sangat tinggi, perkembangan selanjutnya gelar susuhunan diganti menjadi sultan, namun susuhunan dipakai lagi oleh penggantinya yaitu Amangkurat I. Akhimya ketika Mataram pecah menjadi dua (1755) gelar susuhunan dipakai oleh raja-raja Surakarta dan Sultan dipakai oleh raja-raja Yogyakarta. ${ }^{4}$

Pemakaian gelar khalifatullah di Karaton Surakarta masih dipakai sampai pemerintahan Paku Buwana XIII sekarang. Secara lengkap penyebutan raja untuk Karaton Surakarta adalah Senapati Ing Ngalaga Abdurrahman Sayidin Panatagama Khalifatullah. Dari gelar tersebut tampak jelas bahwa raja selain berkedudukan sebagai kepala pemerintahan, panglima tinggi angkatan perang (Senapati Ing Ngalaga), juga kepala bidang keagamaan (Abdurrahman Sayidin Panatagama) serta wali Tuhan di dunia (Khalifatullah). Pemakaian gelar Sayidin

\footnotetext{
${ }^{2}$ Soemarsaid Moertono, Negaara dan Usaha Bina Negara di Jawa Masa Lampau, Jakarta, Yayasan Obor Indonesia. P. 34.

${ }^{3}$ Darsiti Soeratman, Kehidupan Dunia Keraton Surakarta 1890-1939. Yogyakarta.Taman Siswa. 1989. p.4.

${ }^{4}$ Darsiti Soeratman, 1989. p.45.
} 
panatagama khalifatullah berkaitan dengan proses Islamisasi di Jawa. Dengan gelar tersebut berarti raja sudah memeluk agama Islam, lebih dari itu Sunan ${ }^{5}$ secara eksplisit menyatakan sebagai penegak ajaran agama Islam.

Soemarsaid Moertono melihat pemakaian gelar itu dimaksudkan untuk mendapatkan pengakuan dan dukungan kalangan orang-orang Islam. ${ }^{6}$ Secara politik dukungan dari orang-orang Islam sangat dibutuhkan berkaitan dengan penegakan kekuasaan raja. Dengan menganut Islam secara simbolik seorang raja berarti mengisyaratkan perlawanan terhadap pemerintah kolonial Belanda, upayaini diharapkan mendapat dukungan dari orang-orang Islam yang sangat membenci Belanda hingga orang-orang itu memberikan dukungannya kepada raja sebagai penguasa. Pemerintah Belanda berusaha keras supaya para bangsawan tidak memeluk Islam karena ketika bangsawan bahkan seorang raja memeluk Islam, besar kemungkinan terjadi perlawanan terhadap kehadiran orang Eropa di Jawa. $^{7}$

Paku Buwana IV merupakan salah satu raja Karaton Surakarta yang menunjukkan sikap permusuhan kepada Belanda melalui ketaatannya menjalankan ajaran Islam, sebenarnya permusuhan dengan Belanda sudah dinyatakan sejak menduduki jabatan sebagai putra mahkota. Ketaatan Paku Buwana IV dalam menjalankan ajaran Islam terlihat ketika Sunan diminta menari tayuban yang disertai dengan minum-minuman keras. Hal ini oleh Belanda dipandang sebagai sikap perlawanan hingga pemerintah Belanda memandang pentingnya pencegahan penyebaran agama Islam terutama dikalangan bangsawan. $^{8}$

Kisah di atas menunjukkan bahwa proses penyebaran agama Islam telah menyentuh kalangan bangsawan, bahkan seorang raja memeluk Islam dan menjalankan ajarannya dengan taat. Jika raja telah memeluk agama Islam dapat diperkirakan sebagian besar rakyatnya juga mengikuti jejak rajanya yang memeluk agama Islam. Hal ini diduga disebabkan karena hubungan yang sangat dekat antara raja dengan rakyatnya. Dalam tradisi dikenal konsep negara agung di mana kerajaan merupakan pusat kosmologis pemerintahan, sementara hubunganraja dan rakyat dalam bahasa politik kerajaan dinamakan manunggaling kawula gusti. ${ }^{9}$

Penyebaran agama Islam di Jawa tidak berjalan dalam waktu yang singkat, melainkan melalui perjalanan panjang hingga Islam dapat tersebar dan menempati urutan tertinggi jika dihitung jumlah pemeluknya. Penyebaran agama Islam di Jawa tentu melalui perantara serta berbagai sarana yang digunakan sebagai alat pendukung dakwah penyebaran Islam. Salah satu sarana pendukung penyebaran Islam di Pulau Jawa adalah gamelan Sekaten. Perangkat gamelan ini merupakan perangkat gamelan yang dibunyikan untuk memperingati kelahiran Nabi Muhammad SAW, dibunyikan selama satu minggu di Bangsal Pagongan

\footnotetext{
${ }^{5}$ Sebutan lain untuk raja Surakarta

${ }^{6}$ Soemarsaid Moertono, 1985. p. 35.

${ }^{7}$ Sumarsam, gamelan Interaksi Budaya dan Perkembangan Musikal di Jawa. Yogyakarta. Pustaka Pelajar. 2003. p.45.

${ }^{8}$ Riklefs, dalam Sumarsam, 2003. p.45.

${ }^{9}$ Riklefs, 1974
} 
depan Masjid Agung Surakarta.

\section{Perjalanan Gamelan Sekaten}

Berdasarkan cerita gotek (sejarah oral) gamelan Sekaten tidak terlepas dari peranan kerajaan-kerajaan Islam pada saat para wali di Jawa menyebarkan ajaran agama Islam. Sebagaimana diketahui, sebelum masuknya Islam, masyarakat Jawa telah memeluk agama Hindu dan Budha yang menyertakan gamelan atau kesenian sebagai salah satu kegiatan dari upacara ritualnya. Kondisi sosial psikologis masyarakat Jawa semacam itu rupanya menjadi hambatan para wali untuk menyebarkan agama Islam. Maka dalam suatumusyawarah para wali, Sunan Kalijaga mengusulkan agar menggunakan gamelan sebagai daya tarik awal bagi penyebaran agama Islam. Gamelan Sekaten yang digunakan sebagai sarana penyebaran agama Islam di Jawa diduga kuat memiliki nilai-nilai atau unsurunsur Islam dalam perangkat tersebut.

Paku Buwana IV raja Surakarta yang taat menjalankan ajaran Islam menyadari betul kedudukannya sebagai wali Tuhan hingga ia merasa bertanggung jawab terhadap proses dakwah Islam di wilayah hukumnya. Seperti yang telah dilakukan oleh pendahulunya, Paku Buwana IV tetap menggunakan gamelan Sekaten sebagai sarana penyiaran agama Islam. Sebagaimana diketahui bahwa sebenarnya dakwah dengan menggunakan gamelan Sekaten telah dilakukan oleh wali sanga sejak Kasultanan Demak, hingga dapat dikatakan gamelan Sekaten telah ada sejak zaman Demak. Sumber- sumber (literature) Jawa mengatribusikan asal-usul gamelan Sekaten kepada wali sanga, sembilan pemimpin Islam penasehat Sultan Demak I (Raden Patah) pada abad ke $-16 .{ }^{10}$

Penggunaan gamelan Sekaten sebagai sarana penyebaran agama Islam yang dimulai sejak zaman Demak mengalami pasang surut, artinya pada periode tertentu gamelan Sekaten tidak menampakkan eksistensinya. Setelah runtuhnya Demak, tidak ditemukan informasi yang jelas tentang keberadaan gamelan Sekaten. Sampai pada masa kerajaan Pajang dan Mataram awal di bawah pemerintahan Panembahan Senapati dan Panembahan Seda Krapyak keberadaan gamelan Sekaten tidak diinformasikan keberadaannya. Hal ini dapat dimaklumikarena proses peralihan kekuasaan dari Demak ke Pajang terjadi konflik internal atau intrik politik internal kerajaan yang tidak kunjung selesai.

Pada masa Mataram awal di bawah pemerintahan Panembahan Senapati dan Panembahan Seda Krapyak gamelan Sekaten juga belum terlihat eksistensinya. Hal ini berkaitan dengan status Panembahan Senapati dan Panembahan Seda Krapyak yang menggunakan gelar panembahan. Gelar panembahan bukanlah gelar yang seharusnya bagi raja, gelar panembahan lebih memiliki nuansa dan muatan asketik yaitu menyimbolkan seorang yang memiliki keutamaan dalam kehidupan transendental. ${ }^{11}$

Dalam Babad Tanah Djawi juga diberitakan bahwa Senapati "lajeng jumeneng Sultan wonten ing Matawis. Nanging mboten karan: tetiyang kathah

\footnotetext{
${ }^{10}$ Sumarsam, Hayatan gamelan: Kedalaman Lagu, Teori dan Perspektif. Surakarta. STSI Press. 2002. p. 136.

${ }^{11}$ Bambang Sunarto, udaya Musik Karaton Surakarta,' dalam panggung: Jurnal Seni STSI Bandung. XXXVI. Bandung. 2005. [. 13.
} 
sami mastani Panembahan Senapati kemawon. Pemberitaan ini memberi kesan seakan-akan gelar itu kurang tinggi tingkatnya atau tingkat kehormatannya kurang. Kata kemawon yang berarti hanya menunjukkan bahwa gelar panembahan bukanlah gelar bagi seorang raja, tetapi dipakai oleh orang yang derajatnya di bawah raja, gelar panembahan kedudukannya berada di bawah Sultan atau Susuhunan. ${ }^{12}$ Sedangkan gamelan Sekaten merupakan pusaka kepraboning nata atau simbol keagungan seorang raja. Menyadari hal tersebut kedua panembahan itu tidak berani menggunakan gamelan Sekaten sebagai simbol keagungan.

Gamelan Sekaten baru menampakkan eksistensinya lagi pada masa pemerintahan Sultan Agung, raja terbesar Mataram. Sultan Agung berusaha kembali menghidupkan simbol-imbol keagungan seorang raja, sejak saat itugamelan Sekaten sebagai pusaka kepraboning nata mulai menunjukkan keberadaannya.

Sultan Agung membuat gamelan Sekaten "baru" dan diberi nama Kanjeng Kyai Guntur Sari pada tahun Jawa 1566. Angka tahun ini didapat berdasarkan sengkalan ${ }^{13}$ yang tertera pada rancakan ${ }^{14}$ saron $^{15}$ dan demung $^{16}$ gamelan Sekaten Kanjeng Kyai Guntur Sari. Pada bagian tersebut terdapat ukiran yang berupa buah semacam nanas dan buah-buahan yang lain ditempatkan pada sebuah tempat. Ukiran tersebut menurut Pradjapangrawit jika dibaca berbunyi rerenggan wowohan tinata ing wadhah ${ }^{17}$ yang menunjukkan angka tahun 1566. Sedangkan gamelan Sekaten warisan Demak masih menjadi tanya besar apakah dilebur lalu dibuat perangkat gamelan yang lain belum ada keterangan yang pasti. ${ }^{18}$

Peristiwa palihan nagari atau Perjanjian Giyanti (1755) membawa pengaruh bagi keberadaan gamelan Sekaten. Isi perjanjian yang membagi Mataram menjadi Surakarta dan Yogyakarta menyebabkan gamelan Sekaten juga dibagi dua, artinya masing-masing kerajaan tidak mendapat gamelan Sekaten secara lengkap. Hingga menjadi tugas masing-masing kerajaan pecahan itu untuk melengkapi gamelan, di Kasultanan Yogyakarta kemudian dikenal dengangamelan Sekaten Kanjeng Kyai Naga Wilaga, sedangkan di Surakarta masih tetapmenggunakan nama Kanjeng Kyai Guntur Sari.

Pembagian perangkat gamelan Sekaten sangat berkaitan dengan kepercayaan bahwa benda-benda pusaka semacam itu tidak dapat dipisahkan dari raja karena gamelan Sekaten merupakan salah satu pusaka kepraboning nata atau simbol keagungan seorang raja. Dengan adanya benda-benda pusaka itu maka kepercayaan rakyat terhadap raja akan tetap terjaga. Oleh karena itu meskipun terjadi kegoncangan-kegoncangan kekuasaan seperti Perjanjian Giyanti kepercayaan rakyat tetap tidak bergeming kepada raja. Sikap rakyat semacam ini

\footnotetext{
${ }^{12}$ G. Moedjanto, 2002. p. 17-18

13 Kalimat yang memiliki makna angka pada setiap kata, digunakan untuk menunjukkan tahun terjadinya peristiwa atau pembuatan suatu benda yang dianggap pentingj

${ }^{14}$ Resonator yang terbuat dari kayu.

${ }^{15}$ Salah satu instrument gamelan yang berbentuk bilah-bilah.

${ }^{16}$ Salah satu instrument gamelan berbentuk bilah-bilah dan berukuran lebih besar dari saron.

${ }_{17}^{17}$ Bermacam buah-buahan yang ditata pada sebuah tempat.

18 Pradjapangrawit, Serat Sujarah Utawi Riwayating gamelan: Serat Saking Gotek. Surakarta. STSI Press. 1990. p. 47.
} 
erat kaitannya dengan nilai-nilai atau konsep supremasi raja yang disosialisasikan kepada rakyat selama berabad-abad, bahwa raja memiliki kekuatan magis yang melekat pada benda-benda suci milik raja, yang tidak dapat dipisahkan dari raja. ${ }^{19}$

Pada tahun 1788-1820 Paku Buwana IV membuat gamelan Sekaten dengan volume dan ketebalan bentuk yang lebih besar dibandingkan dengan Kanjeng Kyai Guntur Sari yang diberi nama Kanjeng Kyai Guntur Maclu. ${ }^{20}$ Pembuatan gamelan Sekaten ini menunjukkan konsistensi Paku Buwana IV dalam penyebaran Islam dengan menggunakan gamelan Sekaten yang telah ada sejak masa kerajaan Demak. Seperti telah disebutkan di atas bahwa ide penyebaranagama Islam dengan gamelan Sekaten dikemukakan oleh Sunan Kalijaga dalam sebuah pertemuan para wali.

Pradjapangrawit mencatat informasi seputar ide penggunaan gamelan Sekaten dalam penyebaran agama Islam berdasarkan gotek atau sumber oral, ide Sunan Kalijaga itu selengkapnya adalah sebagai berikut:

... ... ... Murih tumunten kasembadan ing sedya, kedah mawi sarana angwonteni kabudayan Jawi ingkang dipun karemi ing tetiyang Jawi; kaanggep pusaka Jawi, inggih punika gangsa. Angivonteni gangsa ingkang dipun pasang wonten ing sacelaking masjid, katabuh ingkang seru sanget, supados kamirengan Baking katebihan. Langkung-langkung ingkang mboten tebih, caged miring cetha sanget. Mesthi kathah tetiyang Jmvi ingkang sami mara, dhateng aningali utawi mirengaken gangsa wau. Amargi sampun sawatawis mboten sami mirengaken gangsa ingkang dipun karemi sanget, kaanggep pusaka Jawi ingkang sakalangkung pinundhi-pundhi. Lha ing nFriku punika panggenanipun nandukaken daya sarana ingkang sae sanget. ${ }^{21}$

(..........Agar segera tercapai tujuannya harus menggunakan sarana kebudayaan Jawa yang sangat disenangi orang Jawa, dianggap pusaka Jawa, yaitu gamelan. Kemudian gamelan tersebut ditabuh di dekat masjid dengan volume yang sangat keras supaya terdengar dari kejauhan. Lebihlebih yang berada di dekatnya dapat mendengarkan dengan jelas sekali. Bisa dipastikan banyak orang Jawa yang datang melihat atau mendengarkan gamelan. Karena sudah agak lama mereka tidak mendengarkan gamelan yang menjadi kesenangan orang Jawa, dianggap pusaka yang sangat dihargai. Di situlah tempat dan sarana yang sangatbagus sekali.....)

Ide penggunaan gamelan Sekaten sebenarnya merupakan jawaban atas kendala yang muncul di lapangan ketika para wali melakukan penyebaran Islam. Setting masyarakat Jawa pada saat itu masih memiliki keyakinan yang sangat kuat terhadap agama Hindu dan Budha sehingga diperlukan alat bantu dalam hal ini gamelan Sekaten untuk memudahkan para wali menyebarkan agama Islam. Strategi dakwah dengan menggunakan gamelan Sekaten yang memiliki suara

\footnotetext{
${ }^{19}$ Fachry Ali, 1986. p. 28.

${ }^{20}$ Pradjapangrawit, 1990. p. 89.

${ }^{21}$ Pradjapangrawit, 1990. p. 25-26.
} 
nyaring dan keras, bentuk fisik yang jauh lebih besar dari gamelan biasa, diperkirakan sangat menarik dan efektif untuk mengumpulkan orang. ProsesIslamisasi seperti itu selanjutnya disebut-sebut sebagai dakwah dengan menggunakan pendekatan kultural. ${ }^{22}$

\section{Gamelan Sekaten Sebagai Sarana Dakwah}

Ide penyebaran agama Islam dengan gamelan Sekaten merupakan sebuah gagasan yang sangat membumi, dalam hal ini Sunan Kalijaga sangat memahami kondisi sosial psikologis masyarakat Jawa pada saat itu. Sebagai seorang wali yang bertugas menyiarkan agama Islam Sunan Kalijaga membekali dirinya dengan pengetahuan tentang kebudayaan dan segala seluk beluk kehidupan masyarakat, termasuk bahasa, adat istiadat, kesusastraan, seni, dan pandangan hidup masyarakat setempat. Hingga tidak mengherankan jika para wali berhasil menjadi penyebar Islam karena mereka mengenal dengan baik, bukan hanya ilmu-ilmu agama tetapi juga kebudayaan Jawa.

Tindakan Sunan Kalijaga dan wali sanga yang menyetujui penggunaan gamelan Sekaten menjadi sarana penyebaran agama Islam merupakan hasil dari sebuah tafsir tentang agama dan kebudayaan yang tepat. Pertemuan antara kebudayaan masyarakat Jawa pada saat itu serta ajaran. Islam yang dibawa wali pada akhirnya tidak merugikan salah satu pihak, artinya antara Islam dan kebudayaan masyarakat Jawa dapat berdampingan, asas utama ajaran Islam yaitu tauhid tidak dikorbankan dan. kebudayaan Jawa dapat dijaga kelestariannya.

Pertemuan antara Islam dan kebudayaan Jawa. dapat dikatakan merupakan pertemuan dua kutub yang sebenarnya berlawanan. Akan tetapi perbedaan itu disikapi para wali dengan tindakan hermeneutik yang kreatif. Tindakan hermeneutik yang kreatif ialah menciptakan perubahan dan transformasikebudayaan sesuai dengan aspirasi baru yang relevan, tetapi mengakar pada sumber otentik ajaran agama. ${ }^{23}$

Bisa dipastikan tindakan yang demikian akan menghasilkan budaya baru yang merupakan titik singgung antara Islam dan kebudayaan Jawa. Damardjati Supadjar menyatakan bahwa titik singgung itu adalah pandangan bahwa budaya Jawa tidak membiarkan kebenaran agama Islam sebagai sri gunung, yaitu bagus jika dipandang dari jauh, upacara-upacara tradisi Jawa mengandung ajaran yang bermaksud mempersiapkan manusia Jawa mendekati kebenaran Islam menjadi sri taman. ${ }^{24}$ Titik singgung itu jika kita lihat pada gamelan Sekaten terlihat pada gendhing-gendhing yang dimainkan dalam perayaan Sekaten serta. wujud fisik gamelan Sekaten.

Aktivitas utama perayaan Sekaten di Surakarta yang diselenggarakan selama tujuh hari untuk memperingati hari kelahiran Nabi Muhammad SAW merupakan pendekatan kebenaran syahadat kepada masyarakat. Sekaten berasal dari kata syahadatain yang berarti dua kalimat syahadat, secara simbolik dua

\footnotetext{
${ }^{22}$ Waridi, 2006. p. 150.

${ }^{23}$ Abdul Hadi WM, "Islam dan Dialog Kebudayaan: Perspektif hermeneutic. Đalam Zakiyuddin Baidhawy dan Matohaharun Jinan (ed), Agama dan Pluralitas Budaya Lokal. Surakarta. Muhammadiyah University Press. 2003. p. 120.

${ }^{24}$ Damardjati Supadjar, Nawang Sari. Yogyakarta. Fajar Pustaka Baru. 2001. p. 83.
} 
kalimat syahadat ini direpresentasikan dalam dua perangkat gamelan Sekaten Kanjeng Kyai Guntur Sari dan Kanjeng Kyai Guntur Madu yang ditabuh secara bergantian. Penempatan dua perangkat gamelan pada dua tempat yang berbeda yaitu Bangsal Pradangga Kidul dan Bangsal Pradangga Lor di halaman Masjid Agung juga merupakan representasi dua kalimat syahadat yaitu syahadat tauhid dan syahadat rasul. ${ }^{25}$

Warna Islam juga nampak pada salah satu bagian dari rangkaian gendhing Sekaten yaitu racikan. Anatomi gendhing sekaten secara lengkap terdiri atas racikan, umpak, gendhing (lagu pokok), dan suwukan. Racikan merupakan sebuah komposisi musikal yang merupakan pengenalan dari setiap gendhing sekaten, yang diekspresikan oleh pengrawit (musisi) melalui instrumen bonang dengan menyajikan serangkaian melodi, selalu disertai dengan bunyi serempak instrumen-instrumen lain dengan nada yang sama. Umpak merupakan potongan melodi yang digunakan sebagai jembatan dari racikan menuju lagu pokok, sedangkan suwukan adalah melodi pendek yang khusus dibunyikan jika gendhing akan berhenti.

Racikan dimaknai sebagai simbolisasi ajaran atas doa yang dibacakan oleh seorang imam. Sedangkan bunyi serempak dari instrumen lain di setiap akhir melodi dipahami sebagai seruan amin dari makmum yang mengikutinya. Hal ini merupakan interjeksi musikal yang berpengharapan agar hubungan imam dan makmummerupakan perpaduan serasi sebagaimana halnya melodi bonang dan suara serempak instrumen lainnya. ${ }^{26}$

Perayaan Sekaten selama tujuh hari di Bangsal Pradangga Masjid Agung Surakarta selalu membunyikan dua gendhing wajib pada awal penyajian, dua gendhing itu adalah Ladrang Rambu dan Ladrang Rangkung. Rambu ditafsirkan berasal dari kata Arab Robbunu yang berarti Allah Tuhanku danRangkung ditafsirkan juga berasal dari kata Arab Rokhun yang berarti jiwa besar atau jiwa yang agung. ${ }^{27}$ Dua gendhing itu harus selalu dibunyikan baik olehgamelan Kanjeng Kyai Guntur Madu di bangsal selatan maupun Kanjeng Kyai Guntur Sari di bangsal utara. Penempatan dan gendhing yang berpasangan dalam penyajiannya merupakan aplikasi konsep budaya Jawa yaitu keseimbangan hidup. Kescimbangan bagi prang Jawa dipandang merupakan hal yang sangat penting karena berkaitan erat dengan citra nilai-nilai etika dan estetika budaya. ${ }^{28}$

Damardjati Supadjar melihat Sekaten memiliki tiga tahapan yang bemafaskan Islam yaitu tafakur, tadzabur, dan tadabbur. ${ }^{29}$ Tahap tafakur memandang seni masih terbatas pada sifat-sifat yang auditif, visual maupun motorik. Pada tahap tadzabur seni diliputi oleh suasana keindahan yang penuh kasih sayang tanpa penonjolan subyek atau pengorbanan obyek, semuanya Baling memaafkan dan mengoreksi. Sedangkan seni pada tahap tadabbur merupakan tahapan olah rasa, olah karsa, lahir dan batin bekerja. Tiga tahap itu menurut

\footnotetext{
${ }^{25}$ Abdul Hadi WM, 2003. p. 122.

${ }^{26}$ Bambang Sunarto, 2005. p. 19-20.

27 Rahayu Supanggah, Bothekan Karawitan. Jakarta. Masyarakat Seni pertunjukan Indonesia. 2000. p. 52-53.

${ }^{28}$ Bambang Sunarto, 2005. p. 19.

${ }^{29}$ Damardjati Supardjar, 2001. p. 336.
} 
Damardjati Supadjar ada pada gamelan Sekaten.

Strategi dakwah atau penyiaran Islam di Jawa yang menggunakan pendekatan kompromis yaitu dengan menggunakan gamelan Sekaten sebagai daya tarik awal pada akhimya membuahkan hasil. Sunan Kalijaga berhasil memanfaatkan potensi budaya lokal untuk keperluan syiar agama Islam. Pradjapangrawit melukiskan keberhasilan penyiaran Islam hampir merata di PulauJawa. ${ }^{30}$ Ada dua pendekatan atau strategi yang mejadikan penyebaran Islam di Jawa berhasil yaitu Islamisasi kultur Jawa dan Jawanisasi Islam.

Islamisasi kultur Jawa yakni mengupayakan agar budaya Jawa tampak bercorak Islam, baik secara formal maupun substansial. Upaya ini dilakukan lewat penggunaan istilah-istilah Islam, penonjolan peran tokoh Islam dalam berbagai cerita dan karya-karya sastra lama, sampai pada penerapan norma-norma Islam dalam aspek kehidupan. Pendekatan kedua disebut Jawanisasi Islam yakni upaya intemalisasi nilai-nilai Islam ke dalam budaya Jawa. Cara pertama diawali dengan menyentuhaspek-aspek formal sehingga simbol-simbol Islam nampak secara nyata dalam budaya Jawa. Pada pendekatan kedua, nama-nama Jawa tetap dipakai akantetapi memuat kandungan nilai-nilai Islam, sehingga Islam menjadi men-Jawa. ${ }^{31}$

Gamelan Sekaten yang muncul karena ide penyebaran agama Islam dandituangkan pelaksanaannya melalui aktivitas perayaan Sekaten dalam rangka memperingati hari kelahiran Nabi Muhammad SAW, diklasifikasikan ke dalam kelompok gamelan pakurmatan yaitu gamelan yang digunakan untuk menghormat sesuatu, suatu peristiwa atau seseorang, lembaga dan sebagainya yang dulu tentunya ada hubungannya dengan keluarga atau sebagai atribut upacara untuk menjaga kebesaran raja/kerajaan dan atau yang terkait dengan kepercayaan; Islam, kejawen, dewa raja, kawula gusti dan sebagainya. ${ }^{32}$ Sebenarnya perangkat gamelan pakurmatan tidak hanya gamelan Sekaten, masih ada gamelan carabalen, gamelan monggang, dan gamelan kodhok ngorek.

Dua perangkat gamelan Sekaten di Karaton Surakarta masing-masing memiliki jumlah dan jenis yang sama. Berikut ini komposisi ricikan yang digunakan pada dua perangkat gamelan Sekaten Karaton Surakarta, masingmasing adalah:

a. Satu rancak bonang yang terdiri dari ricikan bonang dan panembung, ditabuh oleh dua atau tiga orang pengrawit (musisi).

b. Dua rancak demung, setiap demung ditabuh oleh seorang pengrawit.

c. Empat rancak saron barung, setiap rancak ditabuh seorang pengrawit.

d. Dua rancak saron penerus, ditabuh masing-masing oleh seorang pengrawit.

e. Satu rancak kempyang, ditabuh oleh seorang pengrawit.

f. Sepasang atau dua buah gong besar, ditabuh oleh seorang pengrawit.

g. Sebuah bedhug yang digantung pada satu gayor, ditabuh oleh seorang pengrawit.

Fungsi sebagai sarana penyiaran agama Islam menyebabkan gamelan Sekaten memiliki bentuk dan ukuran yang lebih besar dari gamelan pada

\footnotetext{
${ }^{30}$ Pradjapangrawit, 1990. p. 29.

${ }^{31}$ Waridi, 2006. p. 151.

${ }^{32}$ Rahayu Supanggah, 2000. p. 56-57.
} 
umumnya. Gamelan ini memiliki ukuran dan volume yang lebih besar dari gamelan pada umumnya, dengan instrumentasi perkusi sebagai medium utama, ditambah dengan instrumen bedug. Penambahan instrumen bedug merupakan satu bentuk kompromi karena dalam tradisi karawitan Jawa instrumen bedug tidak memberikan kontribusi yang berarti atau bahkan tidak berperan dalam sajiankarawitan, kompromi yang dimaksud adalah penyatuan dua instrumen yang berbeda asal-usul maupun fungsinya. Gamelan yang merupakan produkkebudayaan Jawa dipadu dengan instrumen bedug yang merupakan alat komunikasi peribadatan di masjid. Dengan demikian unsur Islam juga terlihat dari wujud fisik yaitu adanya instrumen bedug.

Proses pengislaman dengan model asimilasi budaya yaitu percampuran dua budaya inilah yang akhirnya menyebabkan munculnya sinkretisme. Secara umum pengertian sinkretisme adalah percampuran antara tradisi Hindu dengan tradisi Islam tanpa melihat apakah percampuran tersebut benar atau salah, murni atau tidaknya suatu agama. Pola seperti ini pula yang melestarikan seni budaya sebagai medium dari ajaran Islam, khususnya yang dilakukan oleh kerajaan. Hal inilah yang menyebabkan karaton menjadi pusat pemerintahan dan aktivitas keagamaan serta pusat pengembangan budaya. ${ }^{33}$

Runtuhnya kerajaan Majapahit yang merupakan dinasti terakhir kerajan Hindu Jawa masih menyisakan tradisi Hinduisme yang menyebabkan proses penyebaran Islam di Jawa mengalami hambatan. Hal ini dikarenakan runtuhnya Majapahit hanya pada tataran formal administratif bukan dalam pengertian tradisi Hinduisme. Kenyataan di lapangan menunjukkan setelahMajapahit runtuh dan kerajaan Islam berdiri di tanah Jawa, tradisi Hindu masih sangat jelas hingga proses pengislaman tanah Jawa harus dilakukan melalui tradisi masyarakat Jawa sendiri.

Kuatnya tradisi Hindu yang menyebabkan para wali mengalami hambatan dalam penyebaran Islam di Jawa. Agama Hindu yang telah berkembang berabad-abad di Jawa sebelum Islam masuk telah meletakkan pondasi bahwa seni merupakan bagian dari ritual, dengan kata lain permasalahan seni dan agamadalam agama Hindu telah berakar kuat karena agama Hindu memasukkan seni dalam persoalan kepercayaan. Hal inilah yang mendorong Sunan Kalijaga melontarkan ide penyebaran agama Islam harus melaluijalur budaya.

Zainudin Fananie menyatakan bahwa kerajaan-kerajaan di Jawa mengembangkan Islam sebagai agama resmi melalui media (seni) budayanya sehingga seni yang dominan dalam proses keagamaan Hindu akhimya mendominasi pula proses ritualisme Islam dan membentuk budaya baru yang disebut kejawen. ${ }^{34}$ Ridin Sofyan juga menyatakan hal yang sama bahwa produkprodukbudaya orang Jawa yang beragama Islam lebih cenderung mengarah pada polarisasi Islam kejawaan atau Jawa keislaman yang selanjutnya dipahami sebagai Islam kejawen. ${ }^{35}$

\footnotetext{
${ }^{33}$ Zainudin Fananie, Pandangan dunia KGPAA Hamangkunagoro I Dalam babad Tutur: Sebuah restrukturisasi Budaya. Surakarta. MUhammadiyah University Press. 1994. p. 131.

${ }^{34}$ Zainudin Fananie, 1990. p. 131.

35 Ridin Sofyan, "Interelasi NIlai Jawa dan Islam dalam Aspek Kepercayaan dan ritual", dalam Darori Amin (ed). Islam \& Kebudayaan Jawa. Yogyakarta. Gama Media. 2002. p. 119-120.
} 
Ide penyebaran agama Islam dengan artefak gamelan Sekaten yang dituangkan dalam aktivitas perayaan Sekaten selama satu minggu bertepatan denganhari kelahiran Nabi Muhammad SAW semakin menunjukkan bahwa aktivitas seni dan prosesi keagamaan merupakan dua hal yang tidak terpisahkan. Peringatan hari-hari besar Islam semacam ini telah mewarnai kehidupan masyarakat Jawa, dalam upacara-upacara, itu termasuk hari kelahiran Nabi Muhammad SAW percampuran antara Hindu dan Islam sangat jelas terlihat prosesritual yang bercorak Islam namun masih menggunakan pola budaya Hindu.

Namun demikian munculnya gamelan Sekaten sebagai sarana penyebaran agama Islam dapat dimaknai sebagai bentuk pemahaman baru terhadap konsep keagamaan yang berkaitan dengan budaya. Meskipunditransformasikan dengan bentuk-bentuk ekspresi budaya lama yang lebih mapan dan berakar kuat, akan tetapi hasilnya merupakan ekspresi budaya baru yaitu bernafaskan Islam sekaligus bercorak Jawa. Dalam hal ini budaya baru yang dihasilkan tidak dapat lagi dikatakan sebagai ekspresi budaya lama yaitu ekspresi budaya Hindu.

Jalaludin Rukmi menyatakan jika suatu makna kerohanian dicetakkan secara intensif ke dalam sebuah bentuk ekspresi budaya, walaupun bentuk ekspresi budaya itu sebenarnya telah berkembang lama, dengan sendirinya bentuk ekspresi itu akan mengalami perubahan dan hadir seakan-akan sebagai sesuatu yang baru. ${ }^{36}$ Dari pernyataan itu semakin jelas bahwa budaya baru hasil percampuran antara kebudayaan Hindu-Jawa dan Islam menghasilkan ekspresi budaya baru yang lain dengan kebudayaan sebelumnya, akan tetapi kebudayaan yang lama tidak hilang begitu saja.

Gamelan Sekaten sebagai benda peninggalan sejarah setidaknya telah menunjukkan bahwa agama dan kebudayaan dapat bersinergi hingga proses pengislaman Jawa tidak mengalami kesulitan. Kesanggupan menafsirkan secara kreatif para penyiar agama Islam di Jawa dalam hal ini para wali telah menghasilkan perubahan dan transformasi kebudayaan sesuai dengan aspirasi budaya Jawa tetapi mengakar pada sumber otentik ajaran Islam.

\section{KESIMPULAN}

${ }^{36}$ Jalaludin Rukmi dalam Abdul Hadi WM, 2003. p. 124. 


\section{Daftar Pustaka}

Abdul Hadi WM,. 2003. "Islam dan Dialog Kebudayaan: perspektif Hermeneutik." Dalam Zakiyuddin Baidhawy dan Mutohaharun Jinan (ed), Agana dan Pluralitas Budaya Lokal. Surakarta. Muhammadiyah University Press.

Bambang Sunarto. 2005. "Budaya Musik Karaton Surakarta", dalam Panggung. Jurnal Seni STSI Bandung. No. XXXVI. 2005. Hal. 9-28. Bandung. STSI Press.

Darsiti Soeratman. 1985. Kehidupan Dunia Kraton Surakarta. 1890-1939. Yogyakarta: Taman Siswa

Damardjati Supadjar. 2001 Nawang Sari. Yogyakarta. Fajar Pustaka Baru.

Fachry ali. 1986. Refleksi Paham Kekuasaan Jawa dalam Indonesia Modern. Jakarta Gramedia

G. Moedjanto. 2002. Konsep Kekuasaan Jawa. Yogyakarta: Kanisius.

JohnPemberton. 200. Jawa: On the Subject ofJava. Yogyakarta: Mata Bangsa

Koentjaraningrat. 1984. Kebudayaan Jawa. Jakarta: Balai Pustaka.

Kuntowijoyo. 2004. Raja, Priyayi, Dan Kawula. Yogyakarta: Ombak

Prajapangrawit. 1990. Serat Sujarah Utawi Riwayating Gamelan: Wedhapradangga (Serat Saking Gotek). Surakarta: STSI Press.

Rahayu Supanggah. 2002. Bothekan Karawitan I. Jakarta: Masyarakat Seni Pertunjukan Indonesia. 
Sofyan. 2002. "Interelasi Nilai Jawa dan Islam dalain Aspek Kepercayaandan Ritual", dalam Darori amin (ed). Islam \&Kebudayaan Jawa. Yogyakarta. Gama Media.

Soemarsaid Moertono. 1985 Negara dan Usaha Bina Negara di Jawa Masa Lampau: Studi Tentang Masa Mataram H, Abad XVI Sampai XIX Jakarta: Yayasan Obor Indonesia.

Sumarsam. 2002. Hayatan Gamelan: Kedalaman Lagu, Teori dan Perspektif. Surakarta. STSI Press.

------. 2003. Gamelan.- Interaksi dan Perkembangan Musikal di Jawa. Yogyakarta. Pustaka Pelajar

Waridi. 2006. Karawitan Jmva Masa Pemerintahan PB X: Perspektif Historic dan Teoritis. Surakarta: ISI Press.

Zainudin Fananie. 1994. Pandangan Dunia KGPAA Hamangkoenagoro I dalam Babad Tutur: Sebuah Restrukturasi Budaya. Surakarta: Muhammadiyah University Press. 